\title{
BIOMASSA EM POVOAMENTOS MONOESPECÍFICOS E MISTOS DE EUCALIPTO E ACÁCIA-NEGRA E DO MILHO EM SISTEMA AGROSSILVICULTURAL
}

\author{
Márcio Viera ${ }^{1}$, Mauro Valdir Schumacher ${ }^{2}$
}

(recebido: 4 de fevereiro de 2010; aceito: 29 de março de 2011)

\begin{abstract}
RESUMO: Objetivou-se, com este estudo, quantificar a produção e a distribuição de biomassa da parte aérea nas plantas em povoamentos monoespecíficos e mistos de eucalipto (híbrido E. urophylla x E. grandis) e acácia-negra (Acacia mearnsii) e do milho (Zea mays) em sistema agrossilvicultural. As avaliações de biomassa (folha, galho, casca e madeira) das espécies florestais, aos 6 e aos 18 meses de idade, foram realizadas nos tratamentos: 100E (100\% de eucalipto + milho); - 100A (100\% de acácia-negra + milho); - 50E:50A (50\% de eucalipto + 50\% de acácia-negra + milho). A avaliação da biomassa do milho (colmo, folha, palha, sabugo e grãos) foi realizada nos tratamentos 100E; 100A; 50E:50A; 75E:25A (75\% de eucalipto + 25\% de acácia-negra + milho); e - 25E:75A (25\% de eucalipto + 75\% de acácia-negra + milho). A produção de biomassa do eucalipto e da acácia-negra, tanto em monocultivo quanto em plantio misto, não diferiu em todas as idades avaliadas, mas, quando avaliada por compartimentos das plantas, verificou-se interação competitiva interespecífica do eucalipto sobre a acácia-negra, ocasionando a redução da formação de biomassa de copa. A produção total de biomassa do milho em sistema agrossilvicultural com eucalipto e acácia-negra em plantios monoespecíficos e mistos não diferiu entre os tratamentos estudados.
\end{abstract}

Palavras-chave: Agrossilvicultura, plantio misto, interações.

\section{BIOMASS IN MONOSPECIFIC AND MIXED STANDS OF EUCALYPTUS AND BLACK WATTLE AND CORN IN AN AGROFORESTRY SYSTEM}

\begin{abstract}
This study aimed at quantifying the production and distribution of aboveground biomass from the plants in monospecific and mixed stands of eucalyptus (hybrid E. urophylla x E. grandis) and black wattle (Acacia mearnsii) and, of corn (Zea mays) in agrosilvicultural systems. The biomass evaluation (leaf, branch, bark and wood) from the forest species at 6 and 18 months of age were performed at the treatments: 100E (100\% of eucalyptus + corn); - 100A (100\% of black wattle + corn); - 50E:50A (50\% of eucalyptus $+50 \%$ of black wattle + corn). The corn biomass evaluation (stem, leaves, straw, cob and grains) was performed at treatments 100E; 100A; 50E:50A; 75E:25A (75\% of eucalyptus $+25 \%$ of black wattle + corn); and - 25E:75A (25\% of eucalyptus $+75 \%$ of black wattle + corn). The biomass production from eucalyptus and from the black wattle, in both monospecific and mixed planting, did not differ in any of the assessed ages but, when evaluated by plants compartments, it was verified an interspecific competitive interaction from the eucalyptus on the black wattle, reducing the formation of crown biomass. The total production of corn biomass in agrosilvicutural systems with eucalyptus and with black wattle in monospecific or mixed plantings did not differ in the studied treatments.
\end{abstract}

Key words: Agroforestry, mixed planting, interactions.

\section{INTRODUÇÃO}

Os sistemas agrossilviculturais são caracterizados pela combinação da produção agrícola e florestal simultânea ou consecutiva, de forma deliberada, na mesma unidade de terreno, almejando um aumento de produtividade através de um rendimento sustentado, por meio da aplicação de técnicas de manejo que visam ao incremento na produção (NAIR, 1989).

A produção e a alocação de biomassa em plantações florestais, principalmente de eucalipto, têm sido muito estudadas ao longo dos anos (COUTO et al., 2004). Contudo, segundo estes autores, em sistemas mais complexos, como o sistema agrossilvicutural, estudos dessa natureza ainda são incipientes, uma vez que a avaliação da produção e alocação de biomassa em cada componente nesses sistemas é mais complexa, devido às interações entre as espécies ao longo do ciclo de produção e ao maior número de componentes envolvidos. Couto et al. (2004) salientam, também, que são indispensáveis essas avaliações para as atividades de manejo sustentável, em relação às práticas culturais aplicadas durante o cultivo e colheita do sistema, e de agrossilvicultura de precisão, sobretudo sob a ótica do planejamento para o melhor aproveitamento pelas diferentes espécies dos recursos inerentes ao sítio.

\footnotetext{
${ }^{1}$ Engenheiro Florestal, Doutorando em Engenharia Florestal - Programa de Pós-graduação em Engenharia Florestal - Centro de Ciências Rurais Universidade Federal de Santa Maria - Cidade Universitária “Prof. Mariano da Rocha Filho” - Av. Roraima, 1000, Bairro Camobi - 97105-900 Santa Maria, RS - vieraflorestal@yahoo.com.br

${ }^{2}$ Engenheiro Florestal, Professor Dr. em Ecologia e Nutrição Florestal - Departamento de Ciências Florestais - Universidade Federal de Santa Maria Cidade Universitária “Prof. Mariano da Rocha Filho”-Av. Roraima, 1000, Camobi-97105-900 - Santa Maria, RS - schumacher@pesquisador.cnpq.br
} 
Em áreas com baixo potencial produtivo, como é o caso da região Sul do Estado do Rio Grande do Sul (Campanha Gaúcha), onde há poucos estudos sobre o desenvolvimento das espécies utilizadas em consórcios, é de suma importância que se tenha o conhecimento técnicocientífico em relação às características dos sistemas de cultivos, para aumentar a produtividade.

Alguns estudos desenvolvidos têm demonstrado a importância dos cultivos consorciados de espécies florestais com milho, como o realizado por Kleinpaul (2008), Marin et al. (2006), Marques (1990) e Moniz (1987). No entanto, ainda pouco se sabe sobre as melhores combinações de plantios mistos de espécies florestais e sobre o potencial desses sistemas para sistemas integrados de produção. Dessa forma, objetivou-se, com o presente estudo, quantificar a produção e a distribuição de biomassa da parte aérea nas plantas em povoamentos monoespecíficos e mistos de eucalipto (híbrido E. urophylla x E. grandis) e acácia-negra (Acacia mearnsii) e do milho (Zea mays) em sistema agrossilvicultural.

\section{MATERIAL E MÉTODOS}

\subsection{Caracterização da área experimental}

O estudo foi realizado em área experimental localizada no município de Bagé na região extremo Sul do Estado do Rio Grande do Sul. Essa área localiza-se nas coordenadas geográficas centrais de $31^{\circ} 14^{\prime}$ '43” latitude Sul e 5404’55” longitude Oeste, com altitude média de 242 $\mathrm{m}$ em relação ao nível médio do mar.

Segundo a classificação climática de Köppen, o tipo de clima fundamental predominante é o Cfa (subtropical úmido), sendo a precipitação média anual na região de $1.264 \mathrm{~mm}$, normalmente bem distribuídos durante o ano. A temperatura média anual é de a $17,9^{\circ} \mathrm{C}$, sendo a média das máximas de $23,5^{\circ} \mathrm{C}$ e a média das temperaturas mínimas de $12,7^{\circ} \mathrm{C}$ (MALUF, 2000). Na Figura 1, pode-se observar o diagrama climático do período de estudo no município de Bagé-RS.

O solo da área experimental é um Argissolo Vermelho-Amarelo Distrófico Latossólico, Unidade de Mapeamento Santa Tecla. Devido à baixa fertilidade natural desses solos (distróficos), forte acidez e alta saturação por alumínio, eles exigem investimentos em corretivos, fertilizantes e sistemas de manejo para alcançar rendimentos satisfatórios (STRECK et al., 2008). O relevo na região é suave-ondulado, estando inserido na região dos campos sulinos, que é essencialmente campestre.

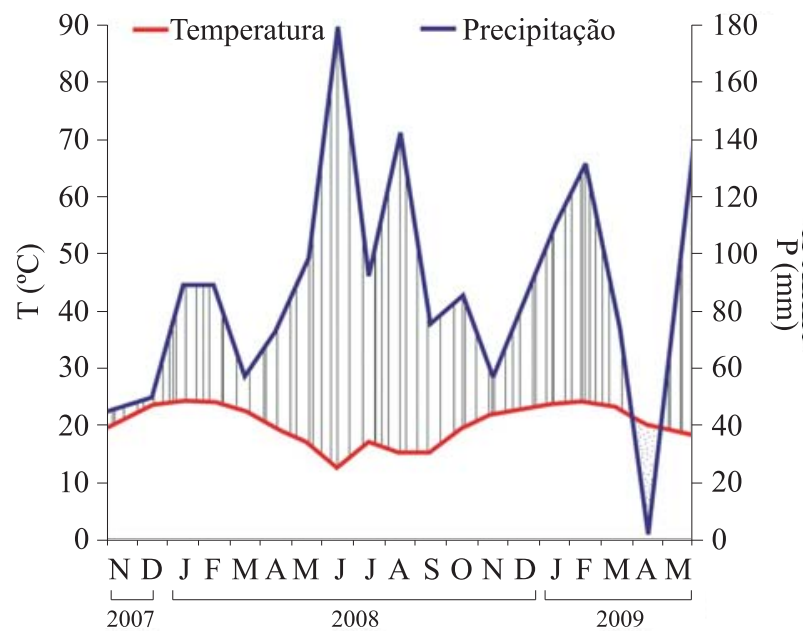

Figura 1 - Diagrama climático da região durante o período de estudo.

Figure 1 - Climatic diagram of the region during the study period.

\subsection{Delineamento e instalação do experimento}

O delineamento experimental adotado foi o de Blocos ao Acaso, com 5 tratamentos e 3 repetições (blocos). Os tratamentos utilizados foram os seguintes: - 100E (100\% de eucalipto + milho); - 100A (100\% de acácia-negra + milho); - 50E:50A (50\% de eucalipto + 50\% de acácia-negra + milho); - 75E:25A (75\% de eucalipto + 25\% de acácia-negra + milho); e - 25E:75A (25\% de eucalipto + 75\% de acácia-negra + milho); sendo que, nos plantios mistos, as espécies florestais foram plantadas em linhas alternadas.

O espaçamento utilizado entre as espécies florestais em todos os tratamentos foi de 4,0 m x 1,5 m e as linhas de plantio foram dispostas em sentido cardinal leste-oeste. A área total de cada parcela foi de $1.224 \mathrm{~m}^{2}$ (25,5 m x 48,0 m), contendo, dessa forma no tratamento 100E, 204 plantas de eucalipto; 100A, 204 plantas de acácia-negra; 50E:50A, 102 plantas de eucalipto e 102 de acácia-negra; 75E:25A, 153 plantas de eucalipto e 51 de acácia-negra e 25E:75A, 51 plantas de eucalipto e 153 de acácia-negra. Foram deixados seis metros entre tratamentos e entre blocos para não ocorrer interferência de um tratamento sobre outro e para sua divisão. Para as avaliações e/ou mensurações, considerou-se bordadura dupla para isolar possíveis interferências externas nos dados obtidos nos tratamentos.

Para a implantação das espécies florestais, foi realizada subsolagem, em uma profundidade média de $50 \mathrm{~cm}$, na linha de plantio, com subsolador de uma 
haste acoplado em trator agrícola. Concomitantemente a essa operação, foi aplicada adubação química, com base na análise de solo, na linha de plantio, com a seguinte formulação: 06:30:06 da fórmula $\mathrm{N}-\mathrm{P}_{2} \mathrm{O}_{5}-\mathrm{K}_{2} \mathrm{O}+7 \%$ de $\mathrm{Ca}+6 \%$ de $\mathrm{S}+0,1 \%$ de $\mathrm{B}+0,5 \%$ de $\mathrm{Cu}$, sendo aplicados $300 \mathrm{~kg} \mathrm{ha}^{-1}$. Em seguida, foram realizadas duas gradagens na linha de plantio, devido à intensa presença de gramíneas.

O plantio das mudas clonais de eucalipto e seminais de acácia-negra foi realizado, manualmente, em novembro de 2007. O controle de formigas foi realizado com formicida granulado, sendo aplicados manualmente seis gramas de formicida na entrelinha de plantio, a cada quatro metros e de forma equidistante. Logo após a implantação das espécies florestais, foi realizada a semeadura do milho em dezembro de 2007. Tal procedimento foi realizado através de uma plantadeira hidráulica acoplada a trator agrícola, com adição de $180 \mathrm{~kg} \mathrm{ha}^{-1}$ de sulfato de amônia. A semeadura de milho foi realizada entre as linhas de eucalipto e/ou acácia-negra, sendo semeadas três linhas de milho, em cada entrelinha de árvores, com distância de 0,80 m entre si e distanciadas 1,2 m das linhas de eucalipto e/ou acácia-negra. Foram utilizadas 5 sementes por metro linear.

\subsection{Amostragem da biomassa}

A biomassa acima do solo das espécies florestais foi determinada nos tratamentos 100E, 100A e 50E:50A aos 6 e aos 18 meses de idade dos plantios. A biomassa florestal foi determinada tendo como referência a árvore média de cada parcela baseada no diâmetro à altura do peito (DAP). Uma vez identificada a árvore de diâmetro médio, com auxílio de fita diamétrica, ela foi abatida (utilizando-se serrote para corte de madeira) e separada nas seguintes frações formadoras da biomassa: madeira, casca, galhos e folhas. Para cada fração, após o abate e separação dos componentes, foi quantificada a massa total em balança digital de precisão (1 g). Em seguida, cada componente teve sua biomassa amostrada, pesada e embalada em sacos plásticos e, posteriormente, enviada ao Laboratório de Ecologia Florestal da Universidade Federal de Santa Maria. Em relação à madeira e à casca, a amostragem procedeu-se da seguinte maneira: distribuíram-se três pontos de amostragem no percorrer do comprimento total do fuste, nas posições medianas das secções resultantes da divisão em três partes iguais do mesmo, resultando em três discos de madeira com casca, com aproximadamente cinco centímetros de espessura, por árvore abatida. Após, separação da madeira e da casca, as amostras foram pesadas para a determinação da massa úmida amostral.
Para as frações galhos e folhas, amostrou-se, de forma aleatória todo o componente, buscando a representatividade em relação às diferentes espessuras e posições na copa.

A biomassa de milho foi quantificada no final do ciclo, safra 2007/2008, na primeira quinzena de maio de 2008. No interior de todos os tratamentos e repetições, alocou-se uma subparcela, com 3,0 m de comprimento por três fileiras de milho como largura (correspondendo ao espaço da entrelinha de plantio das espécies florestais). Todas as plantas de milho contidas no interior dessas parcelas foram abatidas rente ao solo e separadas nas frações colmo, folha, grãos, sabugo e palha. Além desse fracionamento, a biomassa do milho foi determinada em função das diferentes linhas de cultivo, da seguinte maneira: posições de coleta L (E) e L (A) = amostragem da biomassa de milho nas linhas laterais próximas às árvores de eucalipto e acácia-negra, respectivamente e $\mathrm{C}=$ amostragem na linha central. Em seguida, realizou-se a quantificação da biomassa total do material fracionado em balança digital de precisão (1 g), logo após, procedeu-se a amostragem, o que correspondeu a entorno de $50 \mathrm{~g}$ de massa úmida de cada fração. Em laboratório, as amostras dos componentes da biomassa do eucalipto, acácia-negra e do milho foram colocadas para secagem em estufa de circulação e renovação de ar, a $70{ }^{\circ} \mathrm{C}$, até atingirem peso seco constante, sendo então determinada a massa seca em balança digital de precisão $(0,01 \mathrm{~g})$.

\subsection{Análise estatística}

A biomassa total e de cada fração do eucalipto e da acácia-negra foi determinada por meio da multiplicação da massa seca média em cada tratamento pelo número de plantas correspondente a área de um hectare. A biomassa do milho foi estimada com base na multiplicação da massa seca média em cada tratamento (subparcelas de 3,0 m x 4,0 m) pela área de um hectare.

Nos dados, foram aplicados os testes de Bartlett (para verificar a homogeneidade de variância) e de Lilliefors (para comprovar a normalidade dos dados) como pressupostos ao uso da análise de variância para avaliar a biomassa nas diferentes frações dentro do tratamento e entre os tratamentos. Posteriormente, a diferença das médias par-a-par foram analisadas pelo teste de Tukey. As variáveis que não apresentaram normalidade dos dados sofreram transformação aplicando a raiz quadrada ou a inversa da raiz quadrada. As análises estatísticas foram realizadas com o auxílio do programa estatístico ASSISTAT versão 7.5 beta, ao nível de 5\% de probabilidade de erro (SILVA, 2008).

Cerne, Lavras, v. 17, n. 2, p. 259-265, abr./jun. 2011 


\section{RESULTADOS E DISCUSSÃO}

\subsection{Biomassa arbórea}

A alocação de biomassa total acima do solo pelo eucalipto e pela acácia-negra, tanto em monocultivo quanto em plantio misto, não diferiu significativamente $(p>0,05)$ em todas as idades avaliadas (Tabela 1). Mas, quando levada em consideração a compartimentação da biomassa, verificou-se diminuição $(\mathrm{p}<0,05)$ na produção de biomassa de copa (folhas e galhos) da acácia-negra, quando em consórcio com eucalipto, aos 18 meses de idade, em relação ao seu cultivo monoespecífico. O mesmo não ocorreu para o eucalipto. Dessa forma, pode-se observar a interação competitiva interespecífica do eucalipto sobre a acácia-negra, ocasionando a redução da formação de biomassa de copa.

Laclau et al. (2008), estudando povoamento misto de Eucalyptus grandis com Acacia mangium, aos 18 meses de idade, encontraram 70 e $40 \%$ a mais de biomassa de folhas de Acacia mangium em plantio homogêneo em relação ao plantio misto (50A:100E) e monocultivo de Eucalyptus grandis (100E), respectivamente. Esses autores relataram que, a partir de 12 meses de idade, iniciou-se o processo de competição por luz. Em relação à biomassa total, os autores citados anteriormente encontraram $10 \%$ a mais para a combinação mista de 50A:100E do que para monocultivo de eucalipto.

Couto et al. (2004), analisando a produção de biomassa de plantio integrado de clones de híbridos naturais de eucalipto com um ano de idade em um espaçamento de 10,0 m x 4,0 m em um sistema agrossilvipastoril (arroz, soja e braquiária), encontraram quantidade similar de biomassa para a fração madeira e folhas. O mesmo foi verificado por Coêlho et al. (2007) que, estudando a interação entre plantios mistos de Eucalyptus grandis, em espaçamento de 3,0 m x 3,0 m, e leguminosas arbóreas (Mimosa scabrella, Mimosa caesalpiniaefolia e Acacia mangium) plantadas entre as plantas de eucalipto, em linhas alternadas, na proporção de $50 \%$, aos dois anos de idade, observaram que não houve diferenças significativas para a produção de biomassa de tronco e parte aérea (folha, galho e casca) do eucalipto em cultivo monoespecífico ou misto.

A biomassa acima do solo, tanto para o eucalipto quanto para a acácia-negra, independentemente de ser de povoamento monoespecífico ou misto, apresentou a mesma ordem de alocação (folhas $>$ madeira $>$ galhos $>$ casca) aos 6 meses de idade, quando a copa era responsável por mais de 50\% da biomassa total. Já aos 18 meses, ocorreu modificação da prioridade de alocação da biomassa entre as espécies e componentes. Para o eucalipto, a sequência de alocação foi a seguinte: madeira $>$ galhos $>$ folhas $>$ casca. No entanto, a acácia-negra apresentou alocação de biomassa de folhas superior à de galhos e, de forma geral, ao contrário do que ocorreu aos 6 meses, mais de $50 \%$ da biomassa total foi composto pelo tronco (madeira + casca).

Tabela 1 - Produção e distribuição de biomassa em povoamentos monoespecíficos e mistos de eucalipto e acácia-negra, plantados em sistema agrossilvicultural com milho, aos 6 e 18 meses de idade.

Table 1 - Biomass production and distribution in monospecific and mixed stands of eucalyptus and black wattle, planted in agroforestry systems with corn, at 6 and 18 months of age.

\begin{tabular}{|c|c|c|c|c|c|c|}
\hline \multirow{2}{*}{ Trat. } & \multirow{2}{*}{ Idade (meses) } & \multicolumn{5}{|c|}{ Biomassa $\left(\mathrm{kg} \mathrm{ha}^{-1}\right)$} \\
\hline & & Folhas & Galhos & Casca & Madeira & Total \\
\hline \multirow{2}{*}{$100 \mathrm{E}$} & 6 & $810,2^{(38,3)} A^{*}$ & $553,4^{(26,2)} \mathrm{AB}$ & $162,8^{(7,7)} \mathrm{A}$ & $589,9^{(27,9)} \mathrm{A}$ & $2.116,3^{(100,0)} \mathrm{A}$ \\
\hline & 18 & $3.690,3^{(15,2) b}$ & $6.076,9^{(25,0)} \mathrm{ab}$ & $2.534,4^{(10,4)} \mathrm{a}$ & $11.997,4^{(49,4)} \mathrm{a}$ & $24.299,0^{(100,0)} \mathrm{a}$ \\
\hline \multirow{2}{*}{$100 \mathrm{~A}$} & 6 & $602,1^{(37,7)} \mathrm{A}$ & $235,4^{(14,7)} \mathrm{B}$ & $150,2^{(9,4)} \mathrm{A}$ & $608,6^{(38,1)} \mathrm{A}$ & $1.596,3^{(100,0)} \mathrm{A}$ \\
\hline & 18 & $5.978,0^{(21,1)} \mathbf{a}$ & $5.369,5^{(19,0)} \mathbf{b}$ & $3.163,1^{(11,2)} \mathrm{a}$ & $13.797,8^{(48,7)} \mathrm{a}$ & $28.308,4^{(100,0)} \mathrm{a}$ \\
\hline \multirow{2}{*}{ 50E:50A $(\mathrm{E})^{/ 1}$} & 6 & $988,6^{(36,4)} \mathrm{A}$ & $748,3^{(26,9)} \mathrm{A}$ & $227,4^{8,3)} \mathrm{A}$ & $802,5^{(28,3)} \mathrm{A}$ & $2.783,1^{(100,0)} \mathrm{A}$ \\
\hline & 18 & $4.706,9^{(18,7)} \mathrm{ab}$ & $7.102,5^{(28,2)} \mathrm{a}$ & $1.930,5^{(7,7)} \mathrm{a}$ & $11.432,3^{(45,4)} \mathrm{a}$ & $25.172,2^{(100,0)} \mathrm{a}$ \\
\hline \multirow{2}{*}{ 50E:50A (A $)^{/ 1}$} & 6 & $814,0^{(36,5)} \mathrm{A}$ & $525,5^{(22,8)} \mathrm{AB}$ & $205,9^{(9,2)} \mathrm{A}$ & $737,4{ }^{(31,5)} \mathrm{A}$ & $2.373,99^{(100,0)} \mathrm{A}$ \\
\hline & 18 & $3.804,5^{(14,7)} \mathbf{b}$ & $3.654,7^{(14,1)} \mathbf{c}$ & $1.788,6^{(6,9)} \mathrm{a}$ & $16.664,1^{(64,3)} \mathrm{a}$ & $25.912,0^{(100,0)} \mathrm{a}$ \\
\hline
\end{tabular}

*Letras maiúsculas (6 meses) e minúsculas (18 meses) referem-se à separação dos contrastes de média de cada fração da biomassa nos diferentes tratamentos pelo Teste de Tukey, ao nível de 0,05 de significância. ${ }^{11}$ Para efeito de comparação, na estimativa da biomassa no tratamento misto foi convencionado que cada espécie ocupasse a área total.

Cerne, Lavras, v. 17, n. 2, p. 259-265, abr./jun. 2011 
Essa tendência de alocação de biomassa foi observada por Reis et al. (1985), estudando o acúmulo de biomassa em uma sequência de idade de Eucalyptus grandis plantado no cerrado. Os autores relatam que, na fase inicial de desenvolvimento do povoamento (15 meses de idade) em espaçamento de 3,0 m x 1,5 m, a biomassa contida nos componentes madeira + casca é inferior a $45 \%$ do total da biomassa aérea. Mas, com o passar do tempo, esses componentes iniciaram uma crescente elevação na contribuição, até atingir mais de $85 \%$ da biomassa aérea total, aos 73 meses de idade. Esse comportamento de prioridade de alocação de biomassa acima do solo com a idade dos povoamentos decorre, segundo Schumacher e Poggiani (1993), do fato de que, durante a fase inicial de desenvolvimento de uma floresta, boa parte dos carboidratos é canalizada para a produção de biomassa da copa, mas, com o passar do tempo, quando as copas começam a competir entre si por espaço, a produção relativa do tronco aumenta e a de folhas e ramos diminui gradativamente.

\subsection{Biomassa da cultura agrícola}

A produção total de biomassa do milho consorciado com plantios monoespecíficos e mistos das espécies florestais não diferiu $(p>0,05)$ entre os tratamentos testados (Tabela 2). A mesma produção entre os tratamentos pode ser atribuída ao fato de que não ocorreu competição das espécies florestais com o milho ou essa competição foi à mesma em todos os tratamentos.

Tabela 2 - Produção e distribuição da biomassa do milho em cada tratamento e posição amostral, para a safra 2007/2008.

Table 2 - Biomass production and distribution of corn in each treatment and sampling position for the 2007/2008 harvest.

\begin{tabular}{|c|c|c|c|c|c|c|c|}
\hline \multirow{2}{*}{ Trat. } & \multirow{2}{*}{ Posições } & Folha & Colmo & Palha & Sabugo & Grãos & Total \\
\hline & & \multicolumn{6}{|c|}{$\mathrm{kg} \mathrm{ha}^{-1}$} \\
\hline \multirow{4}{*}{$100 \mathrm{E}$} & $\mathrm{L}(\mathrm{E})^{*}$ & $396,3^{\mathrm{A}}$ ab & $236,8^{\mathrm{A}} \mathrm{a}$ & $110,5^{\mathrm{A}} \mathrm{a}$ & $153,2^{\mathrm{A}} \mathrm{a}$ & $774,8^{\mathrm{A}} \mathrm{a}$ & $1671,6^{\mathrm{A} a}$ \\
\hline & $\mathrm{C}$ & $379,5^{\mathrm{AB}} \mathrm{a}$ & $250,3^{\mathrm{A}} \mathrm{a}$ & $100,7^{\mathrm{AB}}$ a & $144,8^{\mathrm{A}} \mathrm{a}$ & $735,7^{\mathrm{A}} \mathrm{a}$ & $1611,1^{\mathrm{A}} \mathrm{a}$ \\
\hline & $L(E)$ & $221,6^{\mathrm{B}} \mathrm{b}$ & $147,0^{\mathrm{A}} \mathrm{b}$ & $58,6^{\mathrm{B}}$ a & $81,3^{\mathrm{B}}$ a & $414,6^{\mathrm{B}} \mathrm{a}$ & $923,2^{\mathrm{B}} \mathrm{a}$ \\
\hline & Total & $997,5 \mathrm{~A}$ & $634,1 \mathrm{~A}$ & $269,9 \mathrm{~A}$ & 379,3A & $1925,2 \mathrm{~A}$ & $4205,9 \mathrm{~A}$ \\
\hline \multirow{4}{*}{$100 \mathrm{~A}$} & $\mathrm{~L}(\mathrm{~A})$ & $325,6^{\mathrm{B}}$ ab & $205,2^{\mathrm{B}}$ a & $79,5^{\mathrm{B}} \mathrm{a}$ & $111,7^{\mathrm{B}}$ a & $486,8^{\mathrm{A}} \mathrm{a}$ & $1208,7^{\mathrm{B}}$ a \\
\hline & $\mathrm{C}$ & $423,0^{\mathrm{AB}} \mathrm{a}$ & $247,3^{\mathrm{B}} \mathrm{a}$ & $97,8^{\mathrm{AB}} \mathrm{a}$ & $137,0^{\mathrm{AB}} \mathrm{a}$ & $593,9^{\mathrm{A}} \mathrm{a}$ & $1499,0^{\mathrm{AB}} \mathrm{a}$ \\
\hline & $\mathrm{L}(\mathrm{A})$ & $517,6^{\mathrm{A}} \mathrm{a}$ & $392,8^{\mathrm{A}} \mathrm{a}$ & $133,8^{\mathrm{A}} \mathrm{a}$ & $178,7^{\mathrm{A}} \mathrm{a}$ & $724,4^{\mathrm{A}} \mathrm{a}$ & $1947,3^{\mathrm{A}} \mathrm{a}$ \\
\hline & Total & $1266,2 \mathrm{~A}$ & $845,3 \mathrm{~A}$ & $311,1 \mathrm{~A}$ & $427,4 \mathrm{~A}$ & $1805,1 \mathrm{~A}$ & $4654,9 \mathrm{~A}$ \\
\hline \multirow{4}{*}{ 50E:50A } & $L(E)$ & $499,0^{A} a$ & $179,6^{\mathrm{A} a}$ & $111,0^{\mathrm{AB}} \mathrm{a}$ & $146,5^{\mathrm{A}} \mathrm{a}$ & $625,0^{\mathrm{AB}} \mathrm{a}$ & $1561,1^{\mathrm{AB}} \mathrm{a}$ \\
\hline & C & $493,5^{\mathrm{A}} \mathrm{a}$ & $260,3^{\mathrm{A}} \mathrm{a}$ & $132,8^{\mathrm{A}} \mathrm{a}$ & $173,4^{\mathrm{A}} \mathrm{a}$ & $755,2^{\mathrm{A}} \mathrm{a}$ & $1815,1^{\mathrm{A}} \mathrm{a}$ \\
\hline & $\mathrm{L}(\mathrm{A})$ & $268,6^{\mathrm{B}} \mathrm{b}$ & $134,7^{\mathrm{A}} \mathrm{b}$ & $74,3^{\mathrm{B}} \mathrm{a}$ & $96,9^{\mathrm{A}} \mathrm{a}$ & $434,5^{\mathrm{B}} \mathrm{a}$ & $1009,1^{\mathrm{B}} \mathrm{a}$ \\
\hline & Total & $1261,1 \mathrm{~A}$ & $574,6 \mathrm{~A}$ & $318,1 \mathrm{~A}$ & $416,8 \mathrm{~A}$ & $1814,7 \mathrm{~A}$ & 4385,3A \\
\hline \multirow{4}{*}{$75 \mathrm{E}: 25 \mathrm{~A}$} & $\mathrm{~L}(\mathrm{E})$ & $215,1^{\mathrm{B}} b$ & $145,4^{\mathrm{B}}$ a & $74,6^{\mathrm{A}} \mathrm{a}$ & $96,5^{A} a$ & $461,6^{\mathrm{A} a}$ & $993,2^{\mathrm{B}}$ a \\
\hline & C & $437,1^{\mathrm{A}} \mathrm{a}$ & $283,1^{\mathrm{A}} \mathrm{a}$ & $112,2^{\mathrm{A}} \mathrm{a}$ & $145,0^{\mathrm{A}} \mathrm{a}$ & $697,6^{\mathrm{A}} \mathrm{a}$ & $1675,0^{\mathrm{A}} \mathrm{a}$ \\
\hline & $\mathrm{L}(\mathrm{A})$ & $307,7^{\mathrm{AB}} \mathrm{ab}$ & $193,4^{\mathrm{AB}} \mathrm{ab}$ & $101,3^{\mathrm{A}} \mathrm{a}$ & $130,8^{\mathrm{A}} \mathrm{a}$ & $627,0^{\mathrm{A}} \mathrm{a}$ & $1360,2^{\mathrm{AB}} \mathrm{a}$ \\
\hline & Total & $959,9 \mathrm{~A}$ & $621,8 \mathrm{~A}$ & $288,1 \mathrm{~A}$ & $372,3 \mathrm{~A}$ & $1786,2 \mathrm{~A}$ & 4028,3A \\
\hline \multirow{4}{*}{ 25E:75A } & $\mathrm{L}(\mathrm{E})$ & $330,0^{\mathrm{A}} \mathrm{ab}$ & $205,8^{A} a$ & $85,5^{\mathrm{A}} \mathrm{a}$ & $122,6^{\mathrm{A}} \mathrm{a}$ & $582,5^{\mathrm{A} a}$ & $1326,3^{\mathrm{A}} \mathrm{a}$ \\
\hline & C & $338,2^{\mathrm{A}}$ a & $209,7^{\mathrm{A}}$ a & $95,2^{\mathrm{A}} \mathrm{a}$ & $132,3^{\mathrm{A}} \mathrm{a}$ & $606,1^{\mathrm{A}} \mathrm{a}$ & $1381,5^{\mathrm{A}} \mathrm{a}$ \\
\hline & $\mathrm{L}(\mathrm{A})$ & $349,4^{\mathrm{A}} \mathrm{ab}$ & $180,0^{\mathrm{A}} \mathrm{b}$ & $83,2^{\mathrm{A}} \mathrm{a}$ & $119,6^{\mathrm{A}} \mathrm{a}$ & $572,3^{\mathrm{A}} \mathrm{a}$ & $1304,5^{\mathrm{A}} \mathrm{a}$ \\
\hline & Total & $1017,5 \mathrm{~A}$ & $595,5 \mathrm{~A}$ & $263,9 \mathrm{~A}$ & $374,5 \mathrm{~A}$ & $1760,9 \mathrm{~A}$ & $4012,3 \mathrm{~A}$ \\
\hline
\end{tabular}

*Posições de coleta: L (E) e L (A) = coleta da biomassa de milho nas linhas laterais próximas às árvores de eucalipto e acácia-negra, respectivamente; $\mathrm{C}$ = coleta na linha central. Letras sobrescritas referem-se à separação dos contrastes de médias de cada fração da biomassa nas posições de coleta em cada tratamento; letras minúsculas referem-se à separação dos contrastes de médias de cada fração da biomassa nos diferentes tratamentos em cada posição de coleta; e letras maiúsculas referem-se à separação dos contrastes do total de cada fração nos diferentes tratamentos pelo Teste de Tukey ao nível de 0,05 de significância. 
Os principais fatores que poderiam interferir na produção agrícola seriam a concorrência por luminosidade, água e nutrientes.

Em relação a esses fatores, a competição por nutrientes pode ser considerada mínima e não prejudicial ao desenvolvimento do milho, pois o sistema radicular, tanto do eucalipto como da acácia-negra, aos oito meses de idade naquele local, se restringia à ocupação máxima de $125 \mathrm{~cm}$ ao entorno da árvore (VIERA, 2010). E, dessa forma, há uma pequena área de concorrência com o sistema radicular das plantas de milho, pois as linhas de cultivo do milho estão a uma distância média de 120 cm em relação à linha de plantio das árvores.

Porém, se o sistema radicular da acácia-negra não está em contato com as raízes do milho, o benefício esperado através da disponibilização imediata do nitrogênio fixado pela leguminosa não ocorrerá. E, além do mais, como o consórcio é realizado na fase inicial de plantio da acácia-negra, não há a possibilidade de disponibilização de nitrogênio ao milho de outra forma. Devido que, nessa fase, não ocorre liberação de material orgânico (serapilheira) pelas árvores. Segundo Khanna (1997) e Vezzani et al. (2001), na fase inicial, o aumento da disponibilidade de nitrogênio no solo se dá essencialmente pela decomposição de raízes finas e nódulos, e só após a formação da copa é que a leguminosa aumentaria a taxa de ciclagem de nutrientes via serapilheira.

Em relação à prioridade de alocação da biomassa do milho, esta foi igual em todos os tratamentos e posições de amostragem, com uma magnitude da seguinte ordem: grão $>$ folha $>$ colmo $>$ sabugo $>$ palha. Esse mesmo padrão de alocação da biomassa do milho foi verificado por Cantarella e Duarte (2008) e Kleinpaul (2008).

No que se refere às posições de amostragem (linhas laterais e linha central), a prioridade de alocação de biomassa de milho diferiu significativamente $(p<0,05)$ em um ou mais componentes, com exceção do tratamento 25E:75A. A intensidade da colheita praticada no milho pelos produtores rurais, em sistemas agrossilviculturais, é apenas a retirada da espiga (grão + sabugo + palha). Já os demais componentes permanecem no sistema, podendo formar uma camada protetora do solo que diminui os efeitos erosivos, visto que o colmo e as folhas correspondem a aproximadamente $40 \%$ da biomassa total.

\subsection{Produtividade do milho}

Em relação à produtividade em grãos do milho, esta variou de 1.760,9 (25E:75A) a 1.925,2 kg ha-1 (100E), mas sem diferença significativa $(\mathrm{p}>0,05)$ entre os tratamentos
(Tabela 2). Kleinpaul (2008) obteve uma produtividade inferior à deste estudo (1.010,0 a 1.260,0 Kg ha-1), durante a safra 2006/2007, em um sistema agrossilvicultural com o mesmo delineamento desse estudo na região de Bagé.

Considerando que a área efetivamente ocupada com o cultivo do milho corresponda a apenas $60 \%$ da área total do sistema agrossivicultural e que a produtividade média do milho em monocultivo na região de Bagé-RS para essa mesma safra $(2007 / 2008)$ foi de $1.853 \mathrm{~kg} \mathrm{ha}^{-1}$, pode-se afirmar que o consórcio foi produtivo (EMATER-RS/ ASCAR, 2009). Segundo Dubois (1979), as árvores podem funcionar como quebra-ventos, evitando a incidência direta de ventos, o que poderia reduzir o índice de evaporação e gerar a amortização da intensidade de incidência dos ventos, causando efeitos positivos nas características mesoclimáticas. Provavelmente, a redução do índice de evaporação seja o principal fator causador do aumento da produtividade do consórcio, pois, durante todo o período de produção, a região passou por escassez hídrica (baixa pluviosidade), como pode ser verificado no diagrama climático (Figura 1).

\section{CONCLUSÕES}

A alocação de biomassa das espécies florestais não foi alterada em função do cultivo misto, com exceção a biomassa de copa, em que o eucalipto apresentou interação competitiva interespecífica sobre a acácianegra. Mesmo assim, recomenda-se que a prática de cultivo misto de espécies florestais seja adotada pelos produtores silviculturais devido ao sortimento de produtos proporcionado pela presença de duas espécies florestais.

O cultivo do milho pode ser realizado tanto com o eucalipto e/ou acácia-negra em monocultivo, como também com o cultivo misto das espécies florestais, visto que a produtividade não foi influenciada em função da utilização de diferentes arranjos das espécies florestais.

\section{AGRADECIMENTOS}

Ao Conselho Nacional de Desenvolvimento Científico e Tecnológico (CNPq - Brasil) pela bolsa concedida ao primeiro autor e à empresa Votorantim Celulose e Papel Unidade Rio Grande do Sul, pela disponibilização das áreas para estudo e pelo apoio logístico e financeiro. À Eng ${ }^{a}$ Ftal. MSc. Isabel Sandra Kleinpaul pela ajuda na instalação do experimento e aos acadêmicos do curso de graduação em Engenharia Florestal, Raquel Custódio D’Ávila e Edenilson Liberalesso, pela inestimável ajuda nas coletas de dados. 


\section{REFERÊNCIAS}

CANTARELLA, H.; DUARTE, A. P. Manejo da fertilidade do solo para a cultura do milho. In: GALVÃO, J. C. C.; MIRANDA, G. V. Tecnologias de produção do milho. Viçosa, MG: UFV, 2008. p. 139-182.

COÊLHO, S. R. F. et al. Crescimento, nutrição e fixação biológica de nitrogênio em plantios mistos de eucalipto e leguminosas arbóreas. Pesquisa Agropecuária Brasileira, Brasília, v. 42, n. 6, p. 759-768, jun. 2007.

COUTO, L. et al. Produção e alocação de biomassa em um sistema agrossilvipastoril com eucalipto na região do cerrado de Minas Gerais. Biomassa \& Energia, Viçosa, v. 1, n. 4, p. 321-334, out./dez. 2004.

DUBOIS, J. Importância de sistemas de produção agroflorestal para a Amazônia. Belém: IICA-Trópicos, 1979. 18 p.

EMATER-RS/ASCAR. Panorama do milho gaúcho: safra 2007/2008. Disponível em: <http://www.cpact.embrapa. br/eventos/2008/reuniao_milho/pdf/Palestras/Claudio\%20 Doro/claudio_doro.pdf>. Acesso em: 20 nov. 2009.

KHANNA, P. K. Comparison of growth and nutrition of young monocultures and mixed stands of Eucalyptus globulus and Acacia mearnsii. Forest Ecology and Management, Amsterdam, v. 94, n. 1/3, p. 105-113, June 1997.

KLEINPAUL, I. S. Plantio misto de Eucalyptus urograndis e Acacia mearnsii em sistema agroflorestal. 2008. 88 p. Dissertação (Mestrado em Engenharia Florestal) Universidade Federal de Santa Maria, Santa Maria, 2008.

LACLAU, J. P. et al. Mixed-species plantations of Acacia mangium and Eucalyptus grandis in Brazil: 1., growth dynamics and aboveground net primary production. Forest Ecology and Management, Amsterdam, v. 255, n. 12, p. 3905-3917, June 2008.

MALUF, J. R. T. Nova classificação climática do estado do Rio Grande do Sul. Revista Brasileira de Agrometeorologia, Santa Maria, v. 8, n. 1, p. 141-150, jan./jun. 2000.

MARIN, A. M. P.; MENEZES, E. D. S.; SAMPAIO, E. V. S. B. Efeito da Gliricidia sepium sobre nutrientes do solo, microclima e produtividade do milho em sistema agroflorestal no Agreste Paraibano. Revista Brasileira de Ciência do Solo, Viçosa, v. 30, n. 3, p. 555-564, maio/jun. 2006.

MARQUES, L. C. T. Comportamento inicial de paricá, tatajuba e eucalipto, em plantio consorciado com milho e capim-marandu, em Paragominas, Pará. 1990. 73 p. Tese (Doutorado em Ciência Florestal) - Universidade Federal de Viçosa, Viçosa, 1990.

MONIZ, C. V. D. Comportamento inicial do eucalipto (Eucalyptus torelliana F. Muell), em plantio consorciado com milho (Zea mays L.) no Vale do Rio Doce, em Minas Gerais. 1987. 61 f. Dissertação (Mestrado em Ciência Florestal) - Universidade Federal de Viçosa, Viçosa, 1987.

NAIR, P. K. R. Classification of agroforestry systems. In: Agroforestry systems in the tropics. London:

Kluwer Academic, 1989. p. 338.

REIS, M. G. F. et al. Acúmulo de biomassa em uma sequência de idade de Eucalyptus grandis plantado no Cerrado, em duas áreas com diferentes produtividades. Revista Árvore, Viçosa, v. 9, n. 2, p. 149-162, jul./dez. 1985.

SCHUMACHER, M. V.; POGGIANI, F. Produção de biomassa e remoção de nutrientes em povoamentos de Eucalyptus camaldulensis Dehnh, Eucalyptus grandis Hill ex Maiden e Eucalyptus torelliana F. Muell, plantados em Anhembí, SP. Ciência Florestal, Santa Maria, v. 3, n. 1, p. 9-18, jan./dez. 1993.

SILVA, F. de A. S. Assistat versão 7.5 beta. Campina Grande: UFPB, 2008.

STRECK, E. V. et al. Solos do Rio Grande do Sul. 2. ed. Porto Alegre: Emater/RS, 2008. 222 p.

VEZZANI, F. M.; TEDESCO, M. J.; BARROS, N. F. Alterações dos nutrientes no solo e nas plantas em consórcio de eucalipto e acácia-negra. Revista Brasileira de Ciência do Solo, Viçosa, v. 25, n. 1, p. 225-231, jan./mar. 2001.

VIERA, M. Crescimento inicial e produtividade de plantios monoespecíficos e mistos de Eucalyptus urograndis e Acacia mearnsii em sistema agrossilvicultural. 2010. 140 p. Dissertação (Mestrado em Engenharia Florestal) Universidade Federal de Santa Maria, Santa Maria, 2010.

Cerne, Lavras, v. 17, n. 2, p. 259-265, abr./jun. 2011 